\title{
FOCLS ON
}

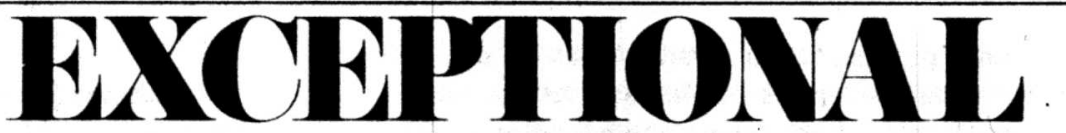

\section{OBSERVATION SYSTEMS AND THE SPECIAL EDUCATION TEACHER}

\section{OBSERVATION SYSTEMS FOR THE SPECIAL CLASSROOM}

\section{Melvyn I. Semmel and Sivasailam Thiagarajan ${ }^{1}$}

It is a well-known phenomenon that eye witnesses differ in their descriptions of even a brief incident. A classroom is such a complex environment, swarming with actions and interactions of different kinds, that if we ask 10 observers to describe what is happening it is very likely that we will have 10 different reports. People's perceptions are based on their background experiences and philosophies; the description from a behaviormodification oriented teacher would differ from that of a diagnostic-prescriptive teacher. Given this fact of different people using different language and methodology to describe the same classroom event, it is no wonder that there is a lack of communication among teachers, supervisors, and other professional personnel. Unless there are a common terminology and common ground rules among educators for talking about teachinglearning interactions, there is bound to be confusion.

As early as 1914, Ernest Horn recognized this problem and established a systematic recording procedure to help him communicate with teachers. He was interested in measuring the extent to which teachers were reaching the individual child by allowing equal opportunities for participation in classroom recitations. Horn decided to disregard all other activities and concentrate on pupil responding behavior. He segmented this area into two categories: pupils reciting and pupils "responding in some other fashion" (e.g., writing on the chalkboard). For each category he devised a symbol: a circle for reciting and a square for responding in some other fashion. Using this system for recording what he saw in the classroom, Horn was able to record and report classroom events clearly and objectively.

Horn's work was one of the first reported uses of observation systems in a classroom context. During the last decade, the idea has attracted a number of investigators and trainers and has given rise to virtually hundreds of observation systems. Although these systems differ considerably from Horn's initial attempts and from each other, they share a number of common attributes. All observation systems provide shorthand techniques for describing specific aspects of classroom interaction and behavior within the

1. Dr. Semmel is Professor and Codirector of the Center for Innovation in Teaching the Handicapped, Indiana University, Bloomington. S. Thiagarajan is the Assistant Director for Instructional Development at the Center.

Love Publishing Company, 1973 
teaching-learning process. Each system uses a set of categories for recording events of interest. At the same time, the system selectively ignores a number of other events outside its domain. Most observation systems are content-free, which enables them to describe what is happening under different classroom conditions. Observation systems do not normally imply value judgments; there are no "good" or "bad" categories. However, a supervisor or a researcher may define desirable patterns of teacher behaviors and interactions based on the observation categories.

\section{WHOSE BEHAVIOR IS OBSERVED}

Most observation systems in use today concentrate on the two important actors in the classroom drama-the teacher and the student. Some deal exclusively with the teacher and others with the student. In the latter case, some deal with the entire class of children while others concentrate on individual children.

The most frequently used observation system, the Flanders' System of Interaction Analysis (Flanders, 1970), is an excellent example of a system that records the behavior of both teacher and students. The categories of this system are listed in Table 1.

The Indiana Behavior Management System (Fink \& Semmel, 1971) also deals with the behaviors of both teacher and students; however, it differs from the Flanders system in that the behavior of only one child is recorded at any given time. The categories of this system are given in Table 2. It will be noted that this system is primarily concerned with affective pupil behaviors and teacher behavior management techniques.

FOCUS ON EXCEPTIONAL CHILDREN is published monthly except June, July, and August as a service to those concerned with mentally retarded and emotionally disturbed children. This journal is abstracted and indexed in Exceptional Child Education Abstrects. Subscription rates, $\$ 9.50$ per year. Copyright 1973, Love Publishing Company. All rights reserved. Reproduction in whole or part without written permission is prohibited. Printed in the United States of America. Second class postage is paid at Denver, Colorado.

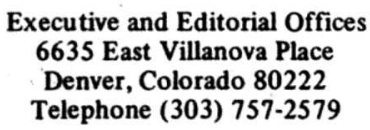

\section{EDITORIAL BOARD}

Edward L. Meyen University of Kansas

Glenn A. Vergason Georgia State University

Richard J. Whelan University of Kansas Medical Center
Sallie Carmachel Keeney Managing Editor
Stanley F. Love Publisher
Table 1

Categories from the Flanders' System of Interaction Analysis*
Teacher Talk Categories

1. Accepts feelings

2. Praises or encourages

3. Accepts ideas

4. Asks questions

5. Lectures

6. Gives direction

7. Criticizes or justifies authority

*Flanders, 1970.
Student Talk Categories

8. Student response

9. Student initiated talk

10. Silence or confusion
Table 2

Categories from the Indiana Behavior Management System II (IBMS-II)*
Pupil Categories

1. On task

2. Self-involvement

3. Noise

4. Verbal interaction

5. Physical interaction

6. Verbal aggression

7. Physical aggression

8. Verbal resistance

9. Physical resistance
*Fink \& Semmel, 1971.
Teacher Categories
10. On task
11. Demand
12. Value-Jaw
13. Conditioned stimulus
14. Criticism
15. Punishment
16. Empathy
17. Interpretive
18. Humor
19. Consequences
20. Redirection
21. Probing

The Teacher Practices Observation Record (Brown, 1970) is an example of observation systems that concentrate exclusively on teacher behavior. Sample categories from this system are shown in Table 3.

Table 3

Sample Categories from the Teacher Practices Observation Record*

I. Nature of the Situation T occupies center of attention. $T$ makes p center of attention. $T$ makes some thing as a thing center of p's attention. 
II. Nature of the Problem

$T$ organizes learning around $Q$ posed by $T$.

$T$ organizes learning around $p$ 's own problem or 0.

$T$ prevents situation which causes $p$ doubt or perplexity.

III. Development of Ideas

$T$ accepts only one answer as being correct.

$T$ permits $p$ to suggest additional or alternative answers.

$T$ expects $p$ to come up with answer $T$ has in mind.

IV. Use of Subject Matter

$T$ collects and analyzes subject matter for $p$.

$T$ has $p$ make his own collection and analysis of subject matter.

$T$ provides $p$ with detailed facts and information.

"Brown, 1970.

ᄀ

In contrast, the Student Observational Form (Lindvall, Yeager, Wang \& Wood, 1970) deals exclusively with pupil behavior and that, too, of an individual pupil. This system is designed for use in individualized instructional settings. Sample categories are found in Table 4.

Table 4

Sample Categories from the Student Observational Form*

I. Independent Work

The student is reading independently.

The student is working independently on a work sheet.

The student is individually listening to a tape recorder.

\section{Teacher-Pupil Work}

The pupil seeks assistance from the teacher.

The pupil receives assistance from the teacher.

The pupil discusses his progress with a teacher.

III. Noninstructional Use of Pupil Time

Pupil spends time at desk not working.

Pupil waits for teacher or clerk to provide lesson materials for him.

Pupil waits for prescription.

\section{Pupil-Pupil Activity}

Pupil asks assistance from another pupil.

Pupil receives assistance from another pupil.
V. Group Activity

Pupil contributes to a group discussion.

Pupil takes a group test under supervision.

Pupil answers a question directed to him.

•Lindvall, et al., 1970.

\section{WHAT BEHAVIOR IS OBSERVED}

Most observation systems deal with verbal behavior, which is not at all surprising when we remember that the predominant behavior in the classroom is verbal. Some systems include a few nonverbal categories; but those that deal exclusively with nonverbal communication are very few-e.g., Interpersonal Communication Behavior Analysis (Buehler \& Richmond, 1963). Both verbal and nonverbal systems may deal with affective (emotional) or cognitive (intellectual) domains. Among other types of categories in observation systems are those of content, classroom climate, and physical environment.

One major variation among categories is the degree of abstraction. At the most general level, a system may have a single category for all teacher questions, requiring a simple discrimination between questions and all other types of teacher statements. At the next level of specificity, the system may have categories of high-level and low-level questions, requiring the observer to differentiate between these two major classes of question-type categories (e.g., factual recall questions, problem-solving questions, etc.).

Figure 1 illustrates various possible levels of generality in a system used to observe behaviors of teachers. Definitions of each category in this figure are given in Table 5.

The degree of specificity of a system depends upon its purpose. The more general the categories are, the more parsimonious the system becomes-i.e., it is possible to reduce classroom interactions to a smaller set of codes. Such observation systems require less time to collect and record information. However, in this reduction process, much valuable information may be lost. Generally, it is easier to train observers on systems with very few specific behavioral categories (e.g., "raising hand"); reliability of such observation systems is higher than those which require the observers to make the more difficult discriminations among broadly inclusive and/or abstract categories.

\section{HOW IS BEHAVIOR OBSERVED AND RECORDED}

In addition to specifying whose behavior and what types of behavior are to be observed, each observation system has a set of ground rules for observing and recording. Based on these ground rules, we may classify observation systems into two major types: (1) a category 
Figure 1

Four Levels of Specificity of Teacher Behavior Categories*

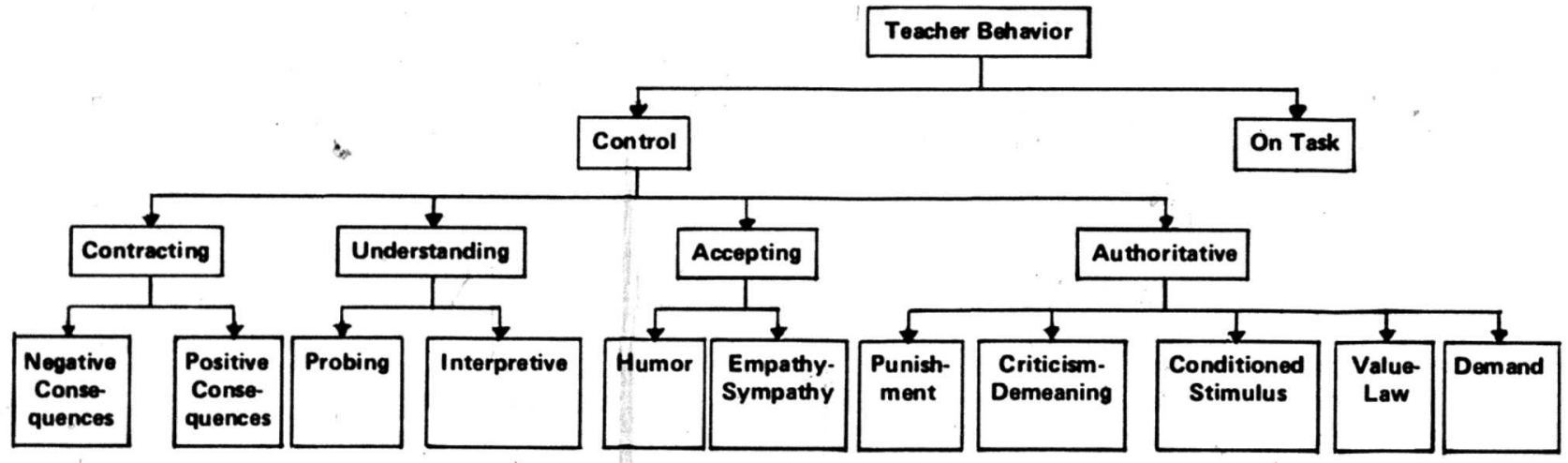

"Fink \& Semmel, 1971.

Table 5

Definitions of Categories in Figure 1

1. Demand

Direct verbal commands to "cease and desist" in firm, authoritative tone. No pupil response expected-e.g., "Be quiet!"

2. Value Law

Teacher explicitly reminds fupil of the established rules of behavior in the classroom by describing or referring to a norm of behavior-e.g., "You know we raise our hands when we wish to speak."

3. Conditioned Stimulus A "signal" for the pupil to stop misbehaving; short phrases and gestures like "O.K.," calling the pupil's name, "Sh," pauses, stares.

4. Criticism-Demeaning Psychological degradation of pupil with verbal attack, criticism, or sarcasm-e.g., “I suppose you think you're being clever?"."

5. Punishment A direct, verbal or physical application of negative sanctions, including loss of privileges and restrictions on pupil freedoms.

6. Empathy-Sympathy Teacher expression of his understanding of pupil's feelings.

7. Humor

Teacher efforts to reduce tension and control pupil behavior by means of jokes, clowning, asides, etc. No intent to criticize pupil.

8. Interpretive

Teacher statements which explain the reason for a pupil's misbehavior-e.g., "You're not paying attention because you don't get enough sleep at night."

9. Probing

Teacher questions to find out (or get the pupil to think about) the reason for his misbehavior. Teacher expects the pupil to answer.

10. Consequences

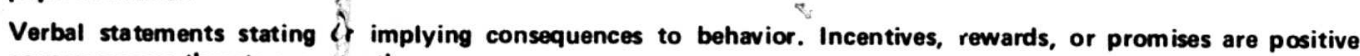
consequences; threats are negative consequences.

system consisting of a small number of categories (usually from 5 to 15) memorized by coders, and (2) a sign system consisting of a larger number of categories (usually from 50 to 200 ) in the form of a printed checklist.

\section{Using Category Systems}

A category system can be used in two different ways. A behavior change unit can be used to code every time the relevant behavior changes from one category to another. Another way is to use a time unit and record the relevant behavior once every three seconds (or some gther time interval).

Let's assume that you are using the behav Jr change unit with the Indiana Behavior Managemer $t$ System
(IBMS) categories listed in Table 2. You have a coding sheet listing all the categories of the system (see Figure 2). You get into the classroom before the lesson begins and locate your target student. (As you may remember, in the IBMS you code the behaviors of the teacher and one particular student.) You let the teacher go through the first few minutes of classroom activities and settle down. When you begin your observation period, you notice that the teacher is explaining something and the target student is listening attentively. You make a hash mark next to categories 1 and 10 on your coding sheet, indicating that both the teacher and the student are "on task." As long as these behaviors continue-i.e., as long as the teacher is teaching and the student is attending-you do not code 
anything else. However, after about five minutes you notice the student turning around and whispering something to his neighbor. You make a hash mark by number 4 (verbal interaction) on your coding sheet. The teacher notices this and yells, "John, be quiet!" You code this as an 11 (demand). The target student begins paying attention, and the teacher continues with his earlier activity. You indicate this by coding 1 and 10 again. You continue this process of making a hash mark every time the behavior of either the teacher or the student changes into some other category of the system. You stop coding at the end of a predetermined time-let's say, 10 minutes. Your coding sheet looks like Figure 2.

From this sheet you get a summary picture of what happened in the classroom during these ten minutes within the categories of IBMS. You notice that John is inclined to verbal interaction and also makes noise by himself and physically interacts with other children. The teacher uses demand, value law, and criticism as major control techniques. Although this gives you an indication of the frequency of various categories of behavior, it does not give you the pattern of behavior nor an indication of how long each behavior lasted. It does not enable you to answer the questions, "Does the teacher use the same control technique with the same type of student 'off task' behavior?" or "How much time is John on task?"

We can use the behavior change unit method of coding with a slight difference to obtain a clearer picture of patterns of behavior. This involves the coder making a sequential list of different behaviors rather than merely making hash marks. A part of this type of sequential coding may look like Figure 3.

Going back to the list of categories, the cryptic numbers are translated in this classroom drama. At the beginning, both the teacher and the target student are on task (10-1). The target student talks to someone else, and the teacher demands that he return to task (10-4-11). The student does so but talks again after some time (1-10-4). The teacher makes another demand, but succeeds only temporarily in controlling the student (11-1-10-4). The teacher now criticizes the student and tries to get him back on task; the student talks back to the teacher aggressively (14-6). With a much lengthier code sheet, it will be possible for us to come up with such generalizations as "most of the time the teacher uses demand when the student talks to someone else," "if repeated demands fail, the teacher uses criticism," and "John doesn't take kindly to teacher criticism." Although this gives more information than the previous frequency table, there is still a major question about duration which is left unanswered. We do not know if John reverts to his verbal interaction behavior within one minute of the teacher demand or after 10 minutes. We do not know if the teacher's criticism is a brief remark or a lengthy sermon.

The time unit method of coding enables us to answer these questions. In this method, the coder records teacher and student behaviors every five seconds. Although this interval may seem to be impossibly short, many coders have been trained to make repeated records using a shorter interval. In using IBMS categories, the coder looks up every

Figure 2

Sample IBMS Coding Sheet

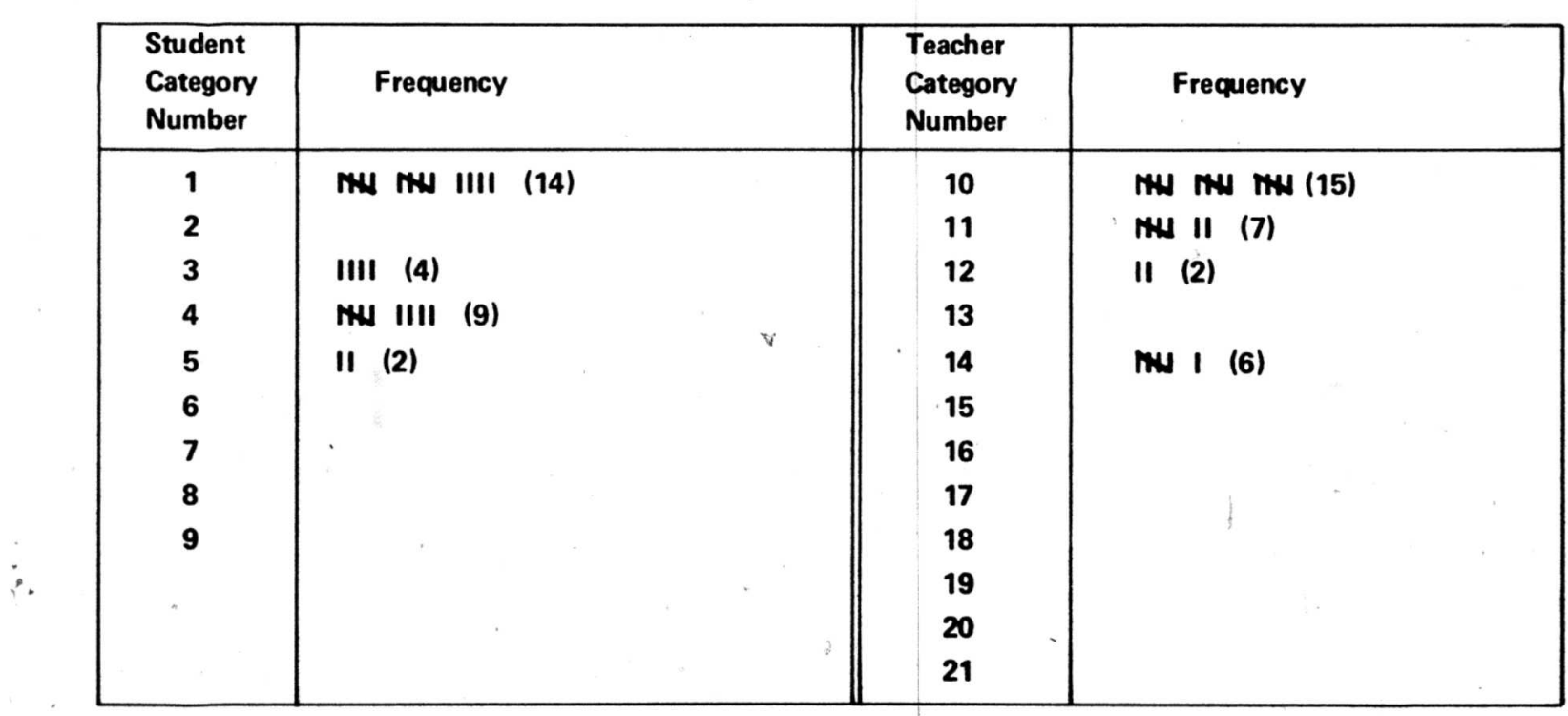


Figure 3

Excerpt from Sequential Coding on IBMS

$10,1,10,4,11,1,10,4,11,1,10,4,14,6, \ldots$

fifth second, notes what the teacher and the target student are doing at that instant and records those behaviors. The resulting coding sheets look like Figure 4. This record indicates that the student was talking for ;0 seconds before the teacher intervened with a brief demand. This sent the student back on task for half a minute, after which he stopped attending to the lesson \&ut did not interact with anyone else. After about a minut of this, the teacher emitted a demand and got the stud nt back on task.

In summary, a category system for classraom obseıvation consists of a small number of categories of teacher and student behavior and a set of ground rules for coding. By tallying the number of times a relevant category of behavior occurs, we obtain a nonevaluative description of the classroom in terms of frequencies of behaviors. By keeping sequential records, we are also able to identify patterns of behaviors. By recording the category of behavior at brief and regular intervals, we obtain a picture of both the pattern and duration of different types of behaviors.

\section{Using a Sign System}

As 'we saw earlier, this second major type of observation system uses lengthy checklists of behaviors. The Florida Climate and Control System, (FLACCS) (Soar, Soar \& Ragosta, 1971), for example, is composed of 158 listed behaviors. In using this system, the coder may, for example, observe classroom interactions for periods of five minutes each. After each period s/he goes through the list of behaviors and checks off each item that was exhibited during that time frame, $S /$ he observes for five minutes, then rates, observes for another five minutes, then rates again, etc. $\mathrm{S} /$ he does not have to remember how many times a particular behavior occurs during each period because even if that behavior occurs more than once during any observation period, it is checked only once. Thus, a sign system merely indicates the type of behaviors that occur; it does not give any indications of the frequency, sequence, or duration of these behaviors. By summing across time periods for any listed behavior, the frequency of occurrence of that behavior can be estimated for the entire observation. Hence, sign systems permit the observer

Figure 4

Excerpt from Time Unit Coding on IBMS

\begin{tabular}{|c|c|c|c|c|c|c|c|c|c|c|c|c|}
\hline \multicolumn{2}{|c|}{$\begin{array}{l}\text { Five-Second } \\
\text { Interval }\end{array}$} & 1 & 2 & 3 & 4 & 5 & 6 & 7 & 8 & 9 & 10 & 11 \\
\hline \multicolumn{2}{|c|}{$\begin{array}{l}\text { Teacher } \\
\text { Behavior }\end{array}$} & 10 & 10 & 10 & 10 & 10 & 10 & 10 & 11 & 10 & 10 & 10 \\
\hline \multicolumn{2}{|c|}{$\begin{array}{l}\text { Student } \\
\text { Behavior }\end{array}$} & 1 & 4 & 4 & 4 & 4 & 4 & 4 & 1 & 1 & 1 & 1 \\
\hline 12 & 13 & 14 & 15 & 16 & 17 & 18 & 19 & 20 & 21 & 22 & 23 & 24 \\
\hline 10 & 10 & 10 & 10 & 10 & 10 & 10 & 10 & 10 & 10 & 10 & 10 & 10 \\
\hline 1 & 1 & 2 & 2 & 2 & 2 & 2 & 2 & 2 & 2 & 2 & 2 & 2 \\
\hline 25 & 26 & 27 & 28 & 29 & 30 & 31 & 32 & 33 & 34 & 35 & & \\
\hline 10 & 11 & 10 & 10 & 10 & 10 & 10 & 10 & 10 & 10 & 10 & & \\
\hline 2 & 1 & 1 & 1 & 1 & 1 & 1 & 1 & 1 & 1 & 1 & & $\Rightarrow$ \\
\hline
\end{tabular}


to record a larger number of behavior categories since $s /$ he neither has to memorize them nor observe and code at the same time. Sign systems are similar to rating scales-the difference being that they demand many ratings replicated across time on some arbitrarily defined, fixed interval schedule.

Another type of observation system, called point-time sampling systems, is somewhat similar to the sign system. The Student Activity Profile (SAP) (Honigman \& Stephens, 1969) referred to earlier is an example of this type used in individualized learning situations. The coder observes the student and records the first unambiguous behavior. $\mathrm{S} / \mathrm{he}$ then moves on to the next student and records his/her behavior. This procedure is repeated until the behaviors of all students in the setting are repeatedly observed and recorded.

\section{APPLICATIONS IN SPECIAL EDUCATION}

Obviously, observation systems are useful in any situation which requires an objective and reliable description of interactive behaviors in the classroom. Although many systems were orginally designed as research instruments for studying teacher behavior, they are now finding increasing use in the training and supervision of teachers. In this section, six major areas of application in special education are discussed; the amount of detail provided corresponds to the relevance of each application to the teacher of exceptional children.

\section{Research: Clarifying Variables}

For a long time, research on teacher behavior and its effects has been inconclusive because of the vagueness of the variables studied. Although controlled experiments in laboratory situations offered a possible solution to this problem, these results seldom transferred to actual classroom conditions. It was in the classroom that observation systems first made their appearance and provided a method for specifying teacher and student variables in unambiguous terms. In special education, observation-system based research may take a number of different forms. In descriptive research settings, information on the interaction between the handicapped child and his/her teacher may be accumulated over a period of time and in different contexts. Analysis of these records should enable researchers to correlate teacher behaviors and student outcomes and eventually specify a theory of instruction of exceptional children (Minskoff, 1967). In another approach, exemplary special education programs may be identified because of their extremely positive or negative outcomes. Systematic observation of teacher and student behaviors in these settings should help us identify desirable competencies for teaching the handicapped (Semmel, Sitko
\& Kreider, 1973). Still another approach may provide more control over the teacher-learning situations. The teacher may be required to exhibit certain categories of behavior based on a specific observation system, and the effect of teacher behavior on student behaviot may be identified. This type of research design permits more confident conclusions about teacher influence on pupil behavior (Semmel, 1972; Schmitt, 1969; Van Every, 1971).

\section{Evaluation: Emphasis on the Process}

Evaluation is similar to research except it involves an assessment of the relative worth of some material or method. In special education, a number of curricular and administrative innovations are being constantly evaluated. The usual design for such evaluations has been to take a - pre-measure (of children, teachers, classroom climate, etc.), administer the new material or method, and take a post-measure of the same variables. Any gains between the pre- and post-measures are attributed to the intervention. In recent years, however, there has been a realization that in addition to measuring these input and outcome variables, measurement of process variables (which specify what happens between these measurements) is also equally important. The relative ineffectiveness of a new curricular package, as determined by the lack of pupil gains between pretest and posttest, may also be due to the inefficient use by teachers. Observation systems are used in these situations to measure process variables and identify the extent to which the actual behavior of teachers corresponds to the prescribed behavior in the teacher's manual. The same technique is also useful in measuring additional independent variables in evaluating administrative and legislative innovations. Project PRIME (Kaufman, Semmel \& Agard, 1973) in Texas, for example, is currently attempting to answer the question, "Under what conditions and for what types of exceptional children is reintegration in regular classrooms a viable alternative?" This project makes extensive use of four different observation systems to collect data on pupil participation in classroom activities, behavior management techniques, types of questions, answers and feedback, and quality of the classroom * climate. Data collected involve regular and special education teachers; normal, educable mentally retarded, and learning disabled children; and integrated and selfcontained classrooms.

\section{Supervision: More Objective Feedback}

One purpose of supervision is to provide feedback to the teacher for the improvement of the quality of teaching. Unfortunately, the role of the supervisor is frequently taken to be evaluative rather than helping. A number of 
problems in teacher-supervisor interactions arise due to different interpretations of the same terms and the lack of clear distinction between facts and opinions expressed by the supervisor. The use of an objective observation system as a common communication mode greatlyíreduces these problems. Different terms now acquire the same meaning. The use of a nonevaluative system forces the supervisor to pay attention to what is happening rather that what is not happening. Information on actual student behaviors is more convincing than the supervisor's optnions, about possible effects of the teacher's behavior. In 'later section of this article, various methods for the use $c^{3}$ observation systems for mutual professional developmer of teachers are outlined. A supervising teacher may find hese suggestions useful in working with his/her teachers.

\section{Student Training}

Children, too, benefit from objective fe Iback about their behaviors. Handicapped students may trained on relevant categories of an observation syst $\mathrm{m}$, and the teacher may cooperatively establish variolis behavioral objectives in terms of these categories. Periodic feedback from the teacher or some other observer should help the student in his/her acquisition of suitable patterns of behavior. A token reinforcement system may be used in conjunction with this systematic feedback to accelerate his/her progress.

\section{Preservice Teacher Training: A Curriculum Based on Observation Systems}

Observation systems are finding increasing use in the preservice training of teachers. The following description of an experimental teacher-training program now being developed at the Center for Innovation in Teaching the Handicapped should give a clearer picture of this application.

The basic training model developed by the senior author for use in this program is shown in Figure 5. The model suggests that the trainee should first learn to liscriminate among relevant teaching performances, then generate or produce each performance when required, and finally evaluate the appropriateness of a particular teaching performance for a given situation (Semmel, 1972; Shuster, 1973). Observation systems have an important role to play in each of these three phases of discrimination, generation, and evaluation. Categories from different systems provide the basis for the trainee to discriminate clearly between different performances. Hence, this phase consists mainly of training on coding methods for selected observation systems. In this process, the trainee learns how to discriminate, for example, between low-level and high-level questions or between criticism and threat. In the genera-

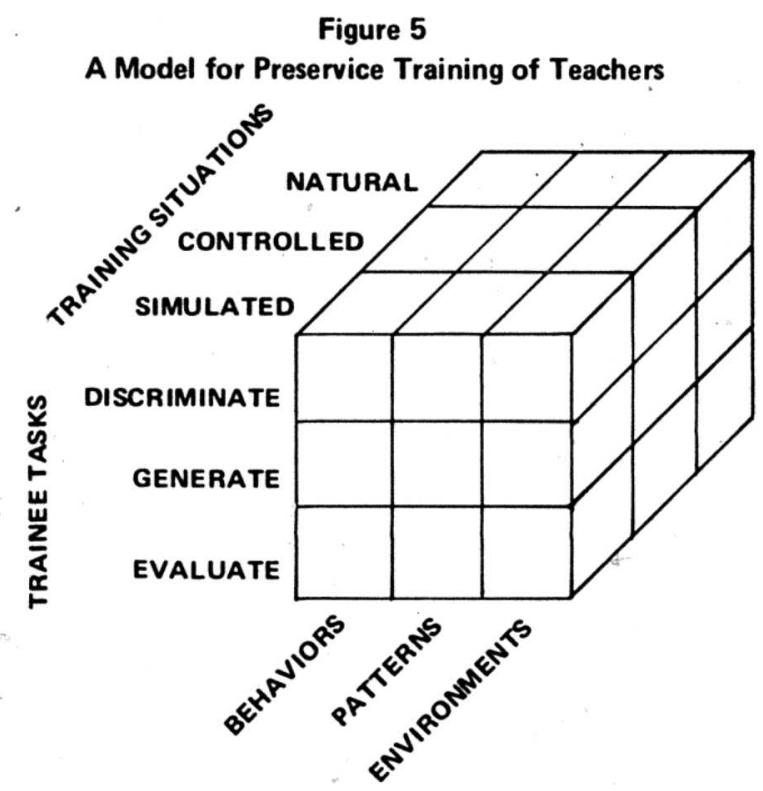

LEVELS OF ANALYSIS OF TEACHING PERFORMANCE

tion phase, the trainee sets up behavior objectives in terms of observation-system categories. For example, s/he may decide to acquire the skill of asking a large proportion of higher-level questions. During practice teaching session, trained observers provide feedback on how well $s /$ he is doing in the selected category. Such feedback becomes a major training technique for attaining the specific competency. In the evaluation phase, observational data on both his/her performance and the students' behaviors are made available to the trainee. By analyzing this information, $s /$ he determines which teacher behaviors are likely to obtain desired student behaviors in the given situation.

Another dimension of this teacher-training model is the continuity of discrimination, generation, and evaluation. As the figure indicates, the trainee moves from individual behaviors to patterns of behaviors and finally to the discrimination, generation and evaluation of teaching environments. For example, s/he may initially work on such individual categories as inference questions, probe, and positive feedback. Later s/he may combine them into such patterns as inference question-probe-positive feedback. Still later, s/he may combine these patterns to create an inductive teaching environment. To offer another example from the behavior management area, such individual behaviors as demand, appeal to authority, criticism, and punishment in combination form sequences which constitute a pattern of teacher control behavior. A combination of these patterns constitutes an authoritarian environment. 
The third dimension of the teacher-training model is the situation in which the trainee is required to perform different operations on different contents. As the figure indicates, this takes place initially under simulated conditions, later in laboratory-like controlled conditions, and finally in public school classrooms. Table 6 provides examples of different phases of training in each of these situations.

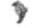

\section{Inservice Teacher Training:}

\section{Self-Evaluation and Mutual Development}

Perhaps the most exciting application of observation systems in special education is in the area of inservice teacher training. Although such training may begin in a workshop situation, the real learning and development takes place in the actual classroom. Whether the teacher works out a formal arrangement with his/her supervisor, or an informal one with his/her colleagues, or prefers to work alone, this on-the-job training involves receiving continuous observation data feedback and changing one's teaching behaviors until a prespecified teaching environment is created. The first time a teacher receives this type of feedback s/he is apt to say, "I didn't realize I do all those things!" Awareness of what one is doing (or not doing) in the classroom is the first step in bringing teaching behaviors under conscious control. Continuous feedback on one's progress in his/her pursuit of the goal is an essential and often sufficient condition for selfdevelopment.

In the developmental process, coding on observation systems may be done either directly in the classroom by one or more of the teacher's peers or by the teacher $\mathrm{him} /$ herself using audio- or videotape recordings of his/her classroom behavior. Each method has its advantages and disadvantages. Recordings preserve privacy and provide a base for leisurely and repeated coding. However, obtaining high-fidelity recordings, especially of the behavior of the entire class, is a complex process requiring specialized skills. In addition, self-analysis and self-confrontation require the highest degree of intellectual honesty and lack of bias. Coding of the "live" performance by a colleague is less biased and more detailed. However, there is no check on the reliability unless a recording is made at the same time or more than one person undertakes the coding.

Various steps in the self-development process are shown in Figure 6. Details of each step are given below so that you may apply the process to your own situation.

1. Specification of goals. In the first step the teacher decides upon the type of teaching-learning environment to be created in the classroom. The teacher may specify all details of this environment or concentrate on just one aspect such as the affective, cognitive, or sociological component. The exact nature of the environment depends upon personal preferences and philosophy. The teacher may decide, for example, to provide a discover-learning environment, a creative atmosphere, a cooperative climate, or an open-classroom situation. At this stage the goal may sound vague and nonbehavioral. However, this is intentional. Our experiences with teachers suggest that beginning with an environment-goal makes them aware of the total picture, whereas beginning with a single target behavior usually makes the effort isolated and trivial. This

Table 6

Sample Training Activities in Different Situations

\begin{tabular}{|c|c|c|c|}
\hline & $\begin{array}{l}\text { Simulated } \\
\text { Situation. }\end{array}$ & $\begin{array}{l}\text { Controlled } \\
\text { Situation }\end{array}$ & $\begin{array}{l}\text { Natural } \\
\text { Situation }\end{array}$ \\
\hline Discrimination & $\begin{array}{l}\text { Trainee codes interactions } \\
\text { from a protocol (record of } \\
\text { a classroom situation). }\end{array}$ & $\begin{array}{l}\text { Trainee codes interactions } \\
\text { in a special experimental } \\
\text { classroom from behind a } \\
\text { one-way mirror. }\end{array}$ & $\begin{array}{l}\text { Trainee undertakes participa } \\
\text { tory observation during } \\
\text { teaching in a public school } \\
\text { classroom. }\end{array}$ \\
\hline Generation & $\begin{array}{l}\text { Trainee performs specific } \\
\text { categories in a micro- } \\
\text { teaching situation. }\end{array}$ & $\begin{array}{l}\text { Trainee performs specific } \\
\text { categories in a tutorial } \\
\text { situation with an excep- } \\
\text { tional child. }\end{array}$ & $\begin{array}{l}\text { Trainee performs specific } \\
\text { categories during actual } \\
\text { teaching in the classroom. }\end{array}$ \\
\hline Evaluation & $\begin{array}{l}\text { Trainee evaluates effects } \\
\text { of teacher behavior in an } \\
\text { instructional simulation } \\
\text { game. }\end{array}$ & $\begin{array}{l}\text { Trainee evaluates effects } \\
\text { of teacher behavior when } \\
\text { given immediate feedback } \\
\text { from trained observers. }\end{array}$ & $\begin{array}{l}\text { Trainee undertakes self- } \\
\text { evaluation in actual class- } \\
\text { room situations. }\end{array}$ \\
\hline
\end{tabular}


environment-goal provides an ideal which can be analyzed later into suitable indicators in terms of observation-system categories.

2. Selecting and learning observation systems. The environment-goal also helps the teacher select a suitable observation system or systems. In contrast to beginning with a system and setting up objectives in terms of its categories, this procedure insures that the "form" will not dictate the "functions" (goals). Unless the teacher is already familiar with a suitable system or has access to an expert, the best source of information is an anthology called Mirrors for Behavior II (Simon \& Boyer; 1970). The 1970 edition of this anthology contains 79 different observation systems; it is extremely likely that whatever the goals may be, one or more existing systems described in this volume will prove appropriate. To simplify the selection process, Mirrors for Behavior II provides brief descriptions of the setting in which each system is used, subject of observation, number of subjects observed, uses of the system, data collection and coding procedures, and coding units. A list of categories of each system is also provided.

Having chosen a system, your next task is to learn it. Although the teacher may decide against coding his/her own behavior, he/she still must learn the system in order to effectively interpret somebody else's coding of his/her classroom. The best way to learn a system is to attend a workshop given by various groups from time to time. If no such workshop is available, locate suitable training materials through the appendix in Mirrors for Behavior II. The essential element in learning a system is to get as much practice in actual classroom coding as early as possible. A useful strategy is to work with a partner, code the same classroom, compare your records and discuss any discrepancies.

3. Operationalizing environmental-goals in terms of system categories. After learning the system, the teacher is ready to compare its categories with the established environment-goal and decide which ones are relevant. Some categories may describe behaviors which are irrelevant to the targeted environment; others may deal with behaviors which are to be reduced or eliminated; still others, with behaviors to be improved or increased. To give a specific example, let's assume that the teacher wishes to create a supportive classroom climate. After mastering the Indiana Behavior Management System (outlined in Table 5), the teacher may decide that the categories of empathysympathy, probing, and interpretive behaviors are to be increased; demand, criticism, conditioned stimulus, and value-law are to be decreased; and positive consequences and humor are of neutral value. Later he/she may ignore the neutral categories either during coding or during data analysis.

4. Selecting target behaviors. The next task is to obtain observation data on normal teaching performance. If the teacher is working with a partner, s/he begins by establishing some ground rules for observation. It is important to assure that the time and situation of observation are varied sufficiently to obtain an overall picture. This means that the teacher is not always coded the first thing in the morning or only during reading or mathematics lessons. If the teacher decides on coding him/herself, s/he must obtain recordings of his/her performances in a variety of situations. Depending upon whether $s /$ he is primarily interested in verbal or nonverbal behaviors, s/he may obtain either audio- or videotape recordings. The former are fairly easy to do with cassette recorders. For videotape recording, some professional assistance is needed. If available, a classroom with a remote TV camera is ideal. Details on suitable recording equipment and its use are usually provided in books which deal with observation systems in the classroom (e.g., Flanders, 1970; Allen, Barnes, Reece \& Roberson, 1970).

The "base-line" data, which is obtained from coding one's own teaching behavior or by having it coded by a colleague, are next compared with the list of categories relevant to the environment-goal. It may be discovered that in some categories the teacher is already performing at the desired level. From the remaining categories s/he may want to choose a few target behaviors to concentrate upon for improving (or reducing) in the near future. Which behaviors to begin with depends upon such factors as how important specific behaviors are to the creation of a targeted environment-goal and how close the teacher is to the desired level. It is generally better to begin with a small number of categories than to attempt a complete metamorphosis overnight.

5. Working on tanget behaviors. Control of teaching behaviors depends largely upon awareness and frequent feedback. Once the teacher has decided upon a set of target behaviors, s/he can consciously attempt to bring them under control. Immediately after specific lessons, at daily or weekly intervals, s/he codes the recorded behavior (or obtains a copy of coding of his/her behavior from a colleague) and evaluates his/her progress. If more improvement is suggested, concentrate upon a smaller number of specific behaviors during ensuing phases. Normally, this process of self-discipline and feedback results in noticeable progress toward the environment-goal in a very short period. If any specific behavior proves to be resistant to change, the teacher may need assistance from his/her supervisor or a master teacher. Once the teacher has reached the desired level of performance in a given set of target behaviors, s/he can move to other sets. Even after 


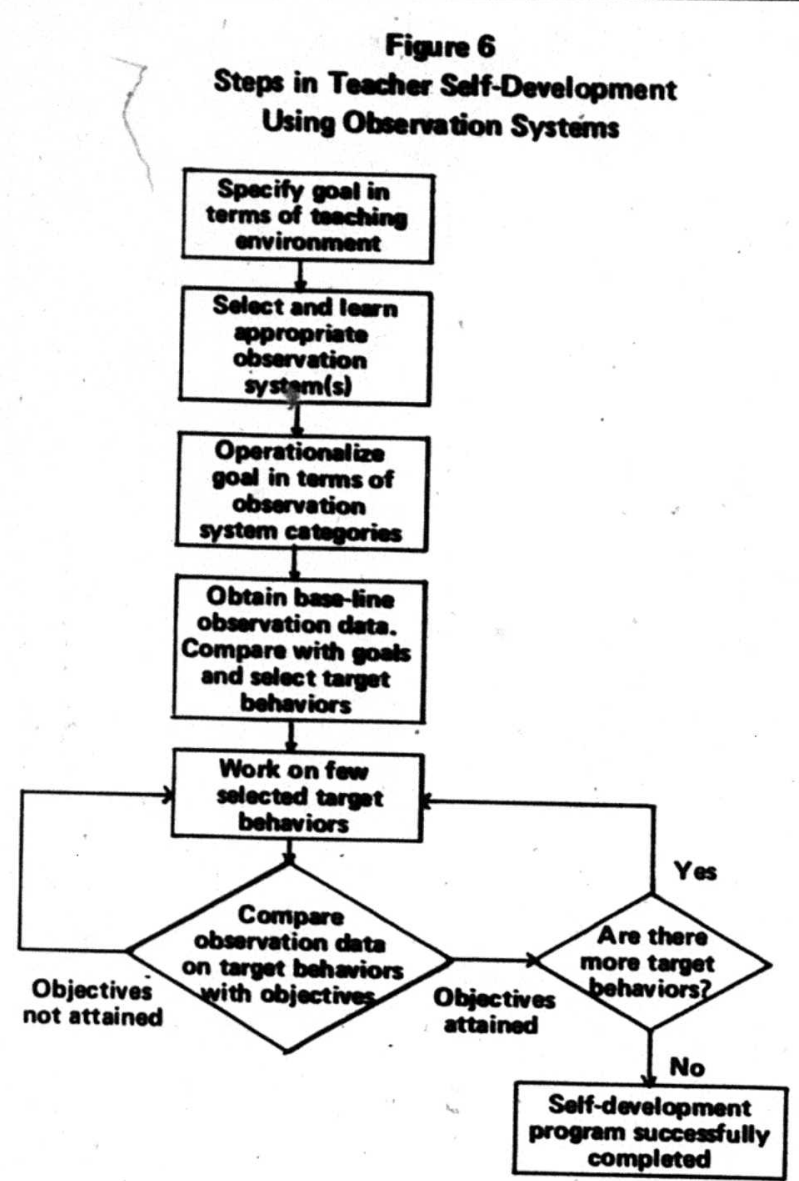

completing the entire set, taking monthly "maintenance checks" should insure that $s /$ he has not reverted to earlier behavior patterns.

The Teacher Empiricist:

\section{Another Application of Observation Systems}

Once a teacher completes the basic self-development program outlined above, s/he may want to move on to a slightly more complex use of observation systems in the classroom. In this procedure, the focus is shifted away from his/her own performance to that of the children. The teacher begins by setting a goal in terms of student behaviors which $s /$ he wishes to elicit. For example, s/he may decide to increase the number of higher-level responses made by mildly handicapped students. Following this decision, $\mathrm{s} / \mathrm{he}$ hypothesizes alternative behaviors which are likely to produce this student outcome. For example, the teacher may decide to increase the number of higher-level questions asked in the classroom or probe lower-level student responses until they are transformed to the higher level, or positively reinforce all higher-level responses while ignoring lower ones. The next task is to locate (or design) an observation system which will include categories for all alternative teacher behaviors and the desired student behaviors. Each of the alternative teacher behaviors are used for a given period of time (e.g., a week) and the classroom is coded. This observation data enables the teacher to check if $s /$ he is really performing at the desired level and what effects the teacher behavior has on the desired student outcomes. After trying out alterhative strategies, the coding will provide some evidence upon which to evaluate their relative effectiveness and to choose a technique or combination of techniques to elicit reliably the types of student outcomes desired.

The use of observation systems for self-development and exploration has to be actively experimented upon by the teacher. The mere use of observation systems will not make an individual a better teacher; however, the systems provide powerful and neutral tools for helping teachers reach their goals toward more effective instruction of exceptional children.

This article is written primarily for teachers. The writers have resisted the discussion of several important technical considerations relative to observation systems which were deemed irrelevant to our target reader population. Readers interested in the psychometric and analytic aspects of the study of teacher-pupil interactions in complex environments are encouraged to contact the authors directly.

The authors are indebted to Ted Hasselbring, Kathy Quirk, and Dorothy Semmel for invaluable assistance in the preparation of this article.

\section{REFERENCES}

Allen, P. M., Barnes, W. D., Reece, J. L. \& Roberson, E. W. Teacher Self-Appraisal: $A$ Way of Looking over Your Own Shoulder. Worthington, Ohio: Charles A. Jones Publishing Company, 1970.

Brown, B. B. "Teacher Practices Observation Record (TPOR)." In A. Simon \& E. G. Boyer (Eds.), Mirrors for Behavior II. Philadelphia: Research for Better Schools, 1970.

Buehler, R. E. \& Richmond, J. F. "Interpersonal Communication Behavior Analysis: A Research Method." Journal of Communication, J3, 1963 (146-55).

Fink, A. H. \& Semmel, M. I. Indiana Behavior Management System-II. Center for Innovation in Teaching the Handicapped, Indiana University, Bloomington, Indiana, 1971.

Flanders, N. A. Analyzing Teaching Behavior. Reading, Mass.: Addison-Wesley Publishing Company, 1970.

Honigman, F. K. \& Stephens, J. "Analyzing Student Functioning in an Individualized Instructional Setting." In Final Report: Demonstration Project in the Processes of Educating Adult Migrants. Fort Lauderdale, Florida: NeaRad, Inc., 1969.

Kaufman, M. J., Semmel, M. I. \& Agard, J. A. Project PRIME: An Qverview. United States Office of Education, Bureau of Education for the Handicapped, Division of Research, Intramural Research Program, in conjunction with the Texas Education Agency, Department of Special Education and Special Schools, Division of Program Evaluation, 1973. 
Lindvall, C. M., Yeager, J. L., Wang, M. \& Wood, C. "Student Observational Form." In A. Simon \& E. G. Boyer (Eds.), Mirrors for Behavior II: An Anthology. Volume A. Philadelphia: Research for Better Schools, Inc., 1970.

Minskoff, E. H. "An Analysis of the Teacher-Pupil Verbal Interaction in Special Classes for the Mentally Retarded." Unpublished doctoral dissertation, Yeshiva University, New York. Office of Education, U.S. Department of Health, Education, and Welfare, Project No. 6-8092, Grant No. $32-42-1700-6008,1967$.

Schmitt, J. K. S. "Modifying Questioning Behavior of Prospective Teachers of Mentally Retarded Children through a ComputerAssisted Teacher Training System (CATTS)." Unpublished doctoral dissertation, University of Michigan, Ann Arbor, 1969.

Semmel, M. I. "Toward the Development of a Computer-Assisted Teacher Training System (CATTS)." In N. A. Flanders \& G. Nuthall (Eds.), The Classroom Behavior of Teachers, published by International Review of Education, XVIII, 4, 1972.

Semmel, M. I., Sitko, M. \& Kreider, J. "The Relationship of Pupil-Teacher Interactions in Classrooms for the TMR to Pupil Gain in Communication Skills." Mental Retardation, December, 1973.

Shuster, S. "A Proposed Performance-Based Training Program for Special Education Teachers." In K. E. Stearns (Ed.), Special Education in Search of Change, published by Viewpoints: Bulletin of the School of Education, Indiana University, 49, 1 , 1973.

Simon, A. \& Boyer, E. D. (Eds.). Mirrors for Behavior II: An Anthology of Observation Instruments, Volume A. Philadelphia: Research for Better Schools, Inc., 1970.

Soar, R. S., Soar, R. M. \& Ragosta, M. The Florida Climate and Control System (FLACCS). Gainesville, Fla: Institute for Development of Human Resources, College of Education, University of Florida, 1971.

Van Every, H. J. F. "The Application of a Computer Assisted Teacher Training System to Speech Therapistraining." Unpublished doctoral dissertation, University of Michigan, Ann Arbor, 1971 .

\section{CLASSBOOM FORUM \\ Edited by Norma Boekel \\ University of Northern Colorado}

\section{PROBLEM 31}

What questions does a teacher ask herself when a pupil fails to respond to her strategies?

1. What in the world is wrong with him?

2. Is it the shape of his head? Could he have a Freudian "block?"

3. Looking at his father... what can you expect?

4. Why was he bored with War and Peace? I loved reading it to him!

5. Why won't he refrain from swearing? Today when I put him in the easy book he said, "Not that goddam Tip again!"

6. What does "Bug off, you creep!" mean?

7. ... But what can' I expect? His parents can't even speak English!

8. Why does he consider his desk a game table when I keep telling him it's a work station?

9. Should I double the amount of arithmetic required since he gets his work done so quickly?

10. The psychologist says he is highly motivated by food, so why doesn't it work when I take away his lunch?

11. How can I continue using the Lovaas techniques if my electric grid won't work?

12. Should I make him read Reality Therapy so I can negotiate contracts with him?

13. Can I tell his parents the truth ... that his former teacher "messed him up?"

14. I wonder if a Binet would help since he had a WISC last year?

15. Are the benefits derived from teaching worth all the problems I have?

16. Will I relax when I'm on tenure?

17. Are obscene gestures as bad as four-letter words?

18. What can you expect in a school where the prineipal wears sweat socks?

19. Why am I so tired? I sit at my desk all day.

20. Why is he so tired? He rides the bus three hours a day.

21. Could it be a result of the "energy crisis?" 